\title{
The effects of under-sleeper pads on sleeper-ballast interaction
}

\author{
P J Gräbe, B F Mtshotana, M M Sebati, E Q Thünemann
}

\begin{abstract}
Under-sleeper pads (USPs), typically made from polyurethane, are used by railways in certain parts of the world to reduce ballast settlement and consequently lengthen the ballast tamping cycle. The rationale behind this relatively new addition to the conventional ballasted track structure is that the pad increases the contact area between the angular ballast particles and the underside of the concrete sleeper, with the effect that ballast breakdown and total track settlement are reduced. This paper describes two experiments on the effects of USPS on four aspects of sleeper-ballast interaction, namely contact area, contact pressure, ballast settlement and ballast breakdown. Static and dynamic tests up to 1 million loading cycles were performed under controlled laboratory conditions on concrete sleepers with and without USPs. Sophisticated pressure sensors revealed an increase in contact area from $12 \%$ to $35 \%$ for static loading tests, and from $8 \%$ to $20 \%$ for dynamic tests, with a resulting $70 \%$ reduction in contact pressure. In addition, a $44 \%$ reduction in ballast settlement and a $23 \%$ reduction in ballast breakdown were achieved by the introduction of USPs. In conclusion it is argued that the introduction of USPs specifically on heavy-haul lines would offer significant advantages with respect to ballast settlement and breakdown. These advantages are most likely to lengthen general ballast tamping and screening cycles, resulting in significant life cycle cost savings.
\end{abstract}

\section{INTRODUCTION}

A conventional track structure consists of the superstructure (i.e. rail, fastening system and sleeper) as well as the substructure (i.e. ballast, subballast and subgrade materials) (Selig \& Waters 1994). With the introduction of concrete sleepers and the phasing out of wooden sleepers in some countries, the traditional track structure became significantly stiffer and an elastic pad or rail pad was introduced between the rail and the concrete sleeper. The rail pad reduces the highfrequency force components that result from dynamic wheel-rail interaction and insulates the rail from the sleeper (Esveld 2001). The next interface where high stress concentrations are present is the underside of the concrete sleeper that is in direct contact with the ballast. With traffic, the concrete and ballast are subjected to high contact stresses which gradually crush the ballast and erode or wear the underside of the sleeper. It is therefore no surprise that ballast breakdown and sleeper wear have been identified as two of the three major sources of ballast fouling (Selig \& Waters 1994). Ballast breakdown is caused by, amongst others, handling during transportation, construction, chemical weathering, tamping and normal traffic damage.

Apart from ballast breakdown, ballast settlement is responsible for gradual track geometry deterioration which necessitates corrective maintenance in the form of track realignment, usually by a mechanised tamping machine in combination with a dynamic track stabiliser (Maree \& Gräbe 1997). It is unfortunate that this process of corrective maintenance unavoidably contributes to further ballast breakdown and degradation. It is exactly this aspect that prompted the development of under-sleeper pads (USPs), a relatively new contribution to the traditional ballast track structure, aimed at reducing ballast and sleeper deterioration, and lengthening the ballast tamping cycle. A life cycle cost calculation, which falls outside the scope of this paper, would be required to compare the benefits of reduced ballast maintenance to the cost of the product. If such a calculation produces a significant cost benefit, the introduction of USPs on passenger, freight and heavy-haul lines should play a significant role in reducing ballast and sleeper maintenance costs. Potocan and Dorfner (2013) addressed this aspect in their research and found the USPs to be financially viable.

\section{BACKGROUND}

The first use of USPs was during the mid1980s on main and high-speed lines in Europe. Since then, several research projects involving numerical, field and laboratory work were carried out to evaluate the effectiveness of USPs.
TECHNICAL PAPER

\section{JOURNAL OF THE SOUTH AFRICAN INSTITUTION OF CIVIL ENGINEERING}

Vol 58 № 2, June 2016, Pages 35-41, Paper 1241

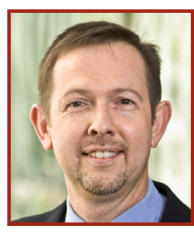

PROF HANNES GRÄBE (Pr Eng, FSAICE) is a civil engineer with 22 years' experience in the fields of track technology, geotechnology, advanced laboratory testing, field investigations, maintenance models and numerical analysis of track structures. He is currently employed by the University of Pretoria as Associate Professor: Transnet Freight Rail Chair in Railway Engineering, where he lectures underand post-graduate courses in railway engineering. He is also responsible for railway research and continuing professional education in the form of short courses presented to industry.

\section{Contact details:}

Transnet Freight Rail Chair in Railway Engineering Department of Civil Engineering

University of Pretoria, Pretoria, 0001, South Africa $\mathrm{T}:+27124204723$

E:hannes.grabe@up.ac.za

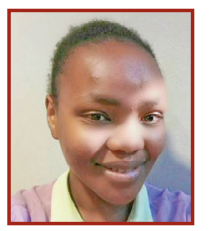

BABALWA MTSHOTANA studied at the University of Pretoria where she obtained a BEng degree in Civil Engineering. She is currently employed at Sectional Poles, where she works on the structural aspects of the design and analysis of telecommunication towers/masts and lighting masts.

\section{Contact details:}

Department of Civil Engineering Sectional Poles (Pty) Ltd University of Pretoria Pretoria, 0001, South Africa 334 Glenwood Road, Lynnwood Park T: +27123488660

E: babalwa@sectionalpoles.co.za

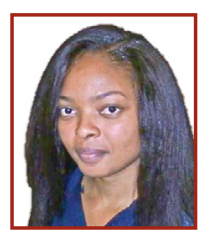

MARTHA SEBATI obtained a BEng degree in Civil Engineering from the University of Pretoria. She is currently employed at the Roads Agency Limpopo as a Trainee Civil Engineer. Her main focus is the construction and maintenance of roads in the Limpopo Province of South Africa.

Contact details:

Department of Civil Engineering Roads Agency Limpopo University of Pretoria Pretoria, 0001, South Africa 26 Rabe Street, Lynnwood Park $\mathrm{T}:+27152844661$

E:koketsosebati@gmail.com

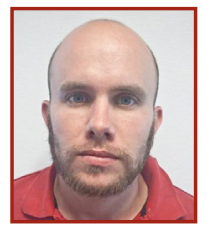

QUINTIN THÜNEMANN graduated from the University of Pretoria with a BEng degree in Civil Engineering. His final-year research project focused on the use of under-sleeper pads when subjected to typical heavy-haul loading conditions.

Contact details:

Department of Civil Engineering

University of Pretoria

Pretoria, 0001, South Africa

$\mathrm{T}:+27124204723$

E:qthunemann@gmail.com

Keywords: under-sleeper pads, ballast, concrete sleepers, ballast settlement, ballast breakdown 


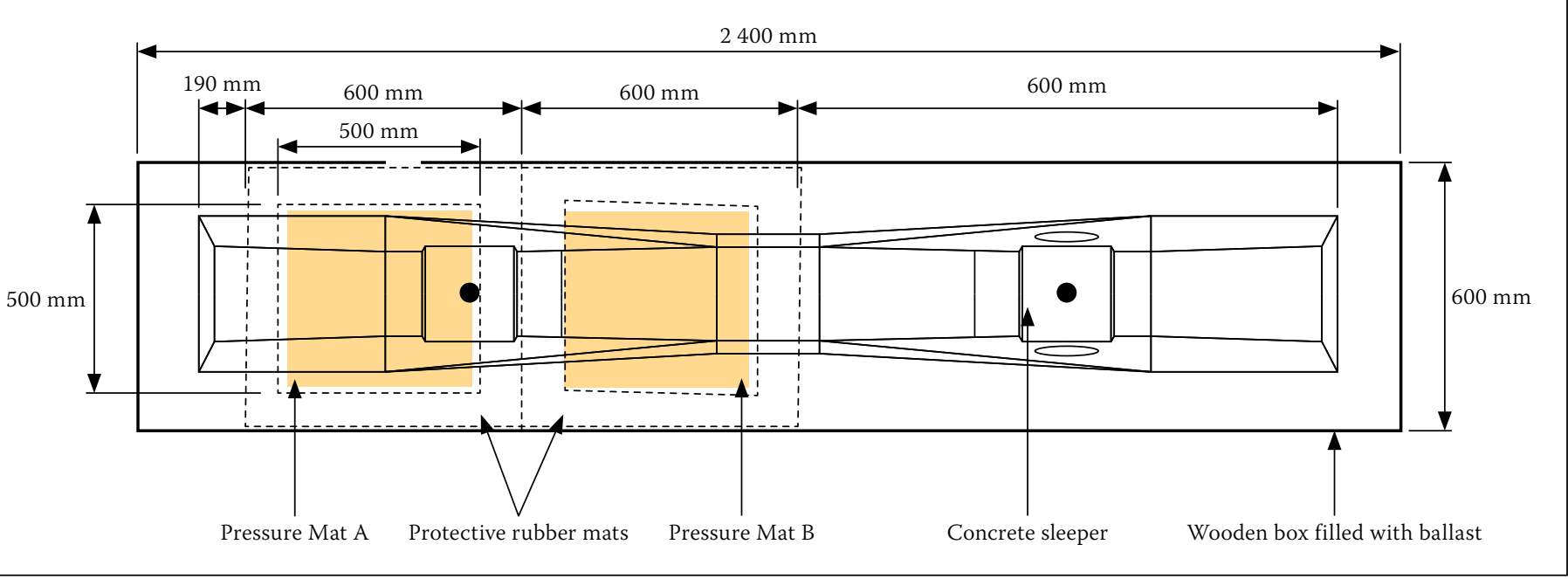

Figure 1 Sleeper and pressure mat test configuration for Experiment 1

Table 1 Ballast grading specification for South African railway lines (Transnet Freight Rail 1998)

\begin{tabular}{|c|c|c|}
\hline $\begin{array}{c}\text { Nominal } \\
\text { aperture } \\
\text { size of sieve } \\
(\mathbf{m m})\end{array}$ & $\begin{array}{c}\text { \% passing } \\
\text { by mass for } \\
\text { ordinary } \\
\text { lines }\end{array}$ & $\begin{array}{c}\text { \% passing } \\
\text { by mass } \\
\text { for heavy- } \\
\text { haul lines }\end{array}$ \\
\hline 75 & 100 & 100 \\
\hline 63 & 100 & $80-100$ \\
\hline 53 & $80-100$ & $40-70$ \\
\hline 37.5 & $40-70$ & $10-30$ \\
\hline 26.5 & $10-30$ & $0-5$ \\
\hline 19.0 & $0-5$ & $0-1$ \\
\hline 13.2 & $0-1$ & 0 \\
\hline
\end{tabular}

Numerical work on USPs includes a parametric characterisation study on the influence of rail pad stiffness, USP stiffness and the stiffness of the ballast and subgrade on dynamic aspects of vehicle-track interaction (Johansson et al 2008). The study concluded that the selection of USP properties with the aim of enhancing track performance will be a compromise between reducing vibration magnitudes in the superstructure on the one hand and vibration magnitudes in the substructure on the other hand. The former would require a stiff USP while the latter would favour a USP with lower stiffness. In another numerical study involving finite element modelling, three different cases were studied, namely the transition from a soft to a stiffer track, a track section with randomly varying stiffness and a track structure with hanging sleepers (Witt 2008). The conclusions from this study highlight the advantages of a USP in each of the three cases and emphasise the importance of choosing the correct USP stiffness.

Research carried out by the Graz University of Technology (TUG) and on Austrian Federal Railways (ÖBB) involved
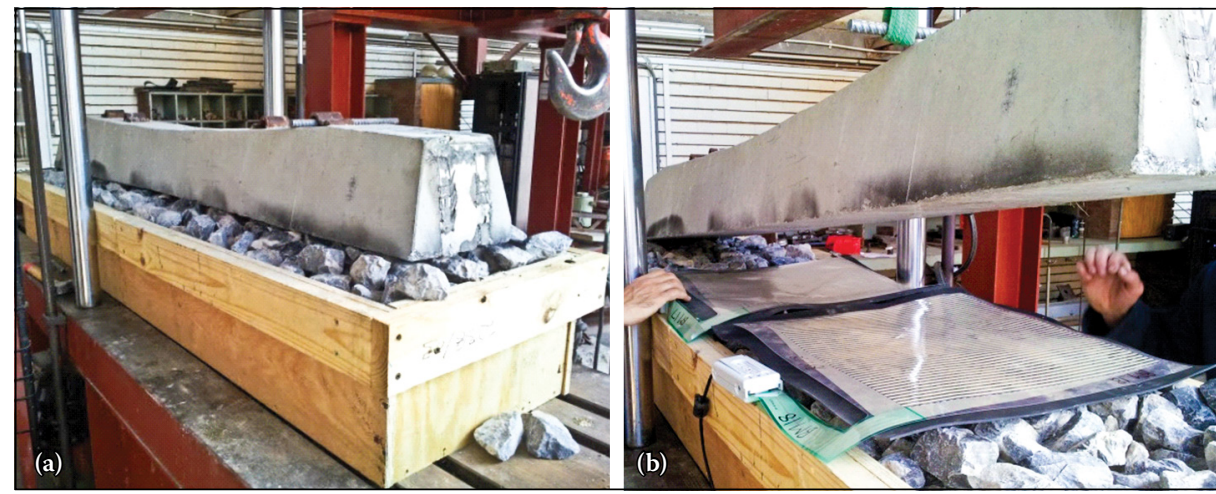

Figure 2 Experiment 1 laboratory setup of PY concrete sleeper in a special ballast box: (a) preparation for test without USP, and (b) positioning of the pressure mats between the sleeper and the ballast

the monitoring of USP installations on hundreds of main line track test sections, with and without USPs. All test sections demonstrated a significantly reduced rate of deterioration, resulting in extended tamping cycles of at least double the original. The researchers also claimed a 30\% life cycle cost reduction of ballasted track as a result of the use of USPs (Veit \& Marschnig 2009; Schilder \& Auer 2009; Marschnig \& Veit 2011). Following these successes, USPs are now used in Austria, Germany, France, Spain and Switzerland in a variety of applications, including high-speed lines, normal main lines, turnouts and sharp curves (Loy 2008; Potocan \& Dorfner 2013).

In a study involving mostly mixed traffic track up to a moderate axle load of 22.5 tons, the researchers are of the opinion that USPs should be even more effective in heavy-haul applications (Veit \& Marschnig 2013). As a minimum, the contact area should be increased from between $5 \%$ and $12 \%$ to approximately $30 \%$, while tamping demand is expected to reduce by at least $50 \%$.

Typical USP installations include main lines, high-speed lines, mixed-freight corridors, turnouts, sharp curves and track transitions. Application of this technology to heavy-haul lines is however not common and, although numerical and parametric studies and a considerable amount of field monitoring tests have been carried out, laboratory simulation of USP installations under heavy-haul conditions have up to now been limited. The research described in this paper is aimed at quantifying the ballast performance improvement brought about by introducing USPs through a series of laboratory tests under controlled conditions.

\section{EXPERIMENTAL WORK}

The objectives of this paper were achieved by carrying out two different laboratory experiments on the effectiveness of under-sleeper pads (USPs). Experiment 1 involved the testing of one $278 \mathrm{~kg}$ concrete sleeper (type PY) on ballast in a wooden box to evaluate the effect of a USP on ballast contact area and ballast pressure. Experiment 2 involved the testing of a half concrete sleeper on ballast in a steel box to evaluate the effect of a USP on ballast settlement and ballast breakdown. Common to both experiments were the ballast aggregate that was used and the type of USP selected for the experiments. Where possible, the conditions on a freight 
or heavy-haul railway line were simulated in terms of the applied loads and the track components chosen for the laboratory tests.

\section{Characteristics of the under-sleeper pad}

The under-sleeper pad used in the laboratory experiments was made from polyurethane and had elastoplastic properties. The pad had a bending modulus of $0.22 \mathrm{~N} / \mathrm{mm}^{3}$ and a static secant stiffness of between $0.01 \mathrm{~N} / \mathrm{mm}^{2}$ and $0.10 \mathrm{~N} / \mathrm{mm}^{2}$. The pad was $10 \mathrm{~mm}$ thick and it was installed directly below the sleeper without a mounting mesh. The pad was manufactured to withstand loads of up to $0.5 \mathrm{~N} / \mathrm{mm}^{2}$, and had a smooth and a relatively rough side with an even texture. The pad was placed between the sleeper and the ballast in such a manner that the rough side made contact with the ballast.

\section{Ballast properties}

The ballast used in the laboratory experiments were selected and graded to comply with the Transnet Freight Rail ballast specification (S406) (Transnet Freight Rail 1998). The document specifies a uniformly graded aggregate that complies with strict minimum criteria regarding soundness, durability, abrasion characteristics, plasticity of fines, flakiness, voids and relative density. The grading envelope of the aggregates is given in Table 1. The ballast used was crushed granite, fully complying with the specification for heavy-haul lines.

\section{Experiment 1}

Experiment 1 involved the testing of a complete PY sleeper on ballast in a specially designed wooden box, as shown in Figure 2 (also refer to Figure 1 for the test configuration). The load was applied to the sleeper with a $900 \mathrm{~mm}$ steel beam resting on the sleeper at the two rail seats. For the purposes of the experiment, two pressure mats or matrix-based tactile surface sensors (MBTSS) were used to measure the contact area and the magnitude of the applied stress. Each pressure mat $(500 \mathrm{~mm} \times 500 \mathrm{~mm}$ ) had 2112 surface sensors positioned in a grid of 44 rows and 48 columns. For protection, the pressure mats were placed between two thin rubber membranes $(600 \mathrm{~mm} \times 600 \mathrm{~mm}$ $x 2 \mathrm{~mm}$ ), one between the sleeper and the pressure mat, and one between the pressure mat and the ballast. The two pressure mats (A and $\mathrm{B}$ ) were positioned to cover the area directly below the point of load application so that the maximum stresses could be measured as shown in Figure 2. Seating of the sleeper was achieved by an initial 1000 cycles to a maximum of $50 \mathrm{kN}$ at a frequency of $2 \mathrm{~Hz}$.

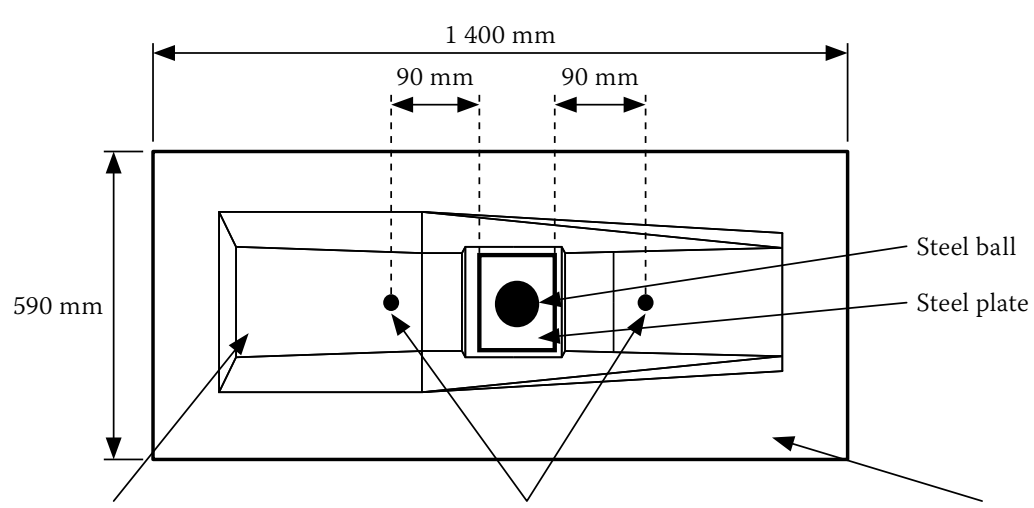

Concrete sleeper

LVDT measurement areas

Steel box filled with ballast

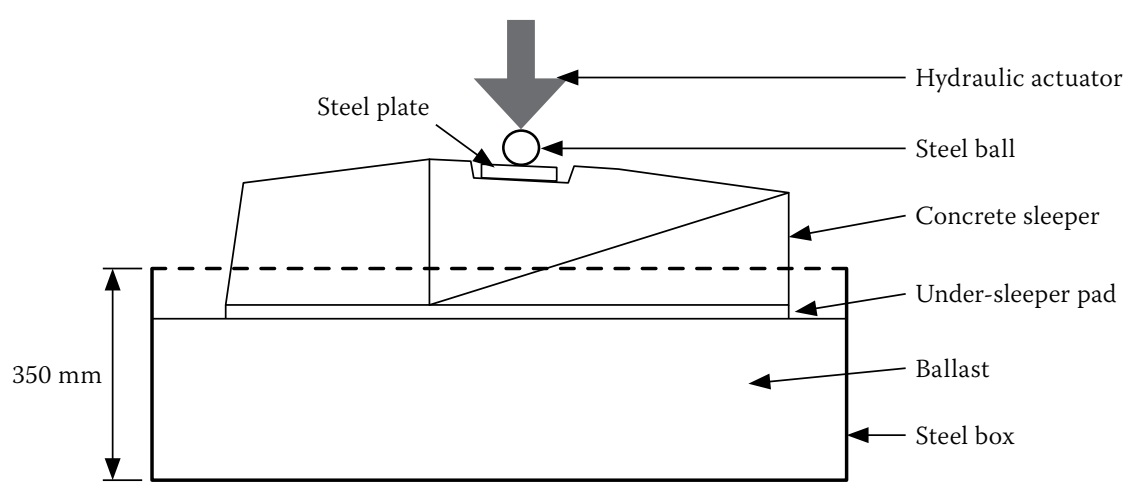

Figure 3 Sleeper dimensions and test layout for Experiment 2
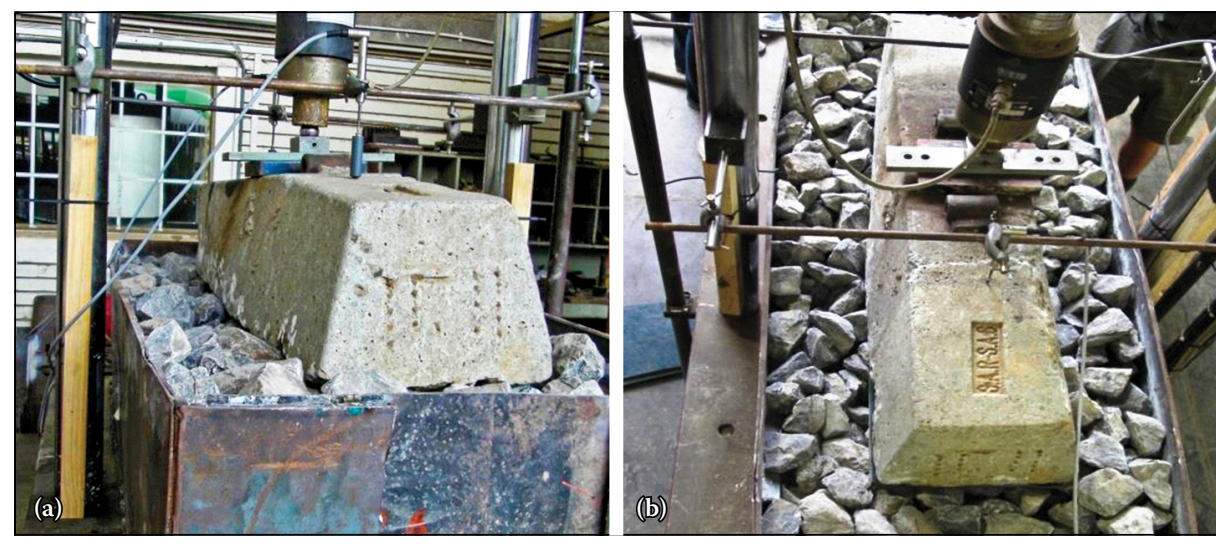

Figure 4 Experiment 2 laboratory setup of a half PY concrete sleeper in a special ballast box with instrumentation to measure the settlement of the sleeper: (a) complete installation for test without USP, and (b) instrumentation and setup for test with USP installed

\section{Experiment 2}

Experiment 2 involved the testing of approximately half a PY sleeper $(1 \mathrm{~m}$ in length) on ballast in a specially designed steel box as shown in Figure 3. The load was applied by an hydraulic actuator on a steel ball at the rail seat. No contact stress measurements were done during this experiment. Two linear variable differential transducers (LVDTs) were, however, used to measure the vertical displacement (settlement) of the sleeper in the ballast box, as depicted in Figure 4. The grading of the ballast was determined before and after the execution of each of the tests.

For this experiment a maximum number of 1 million cycles was arbitrarily chosen as a large enough value to evaluate the long-term performance of the ballast and USPs as a result of cyclic loading. On a heavy-haul line that annually exports 75 million gross tonnes (MGT) of coal, 1 million cycles would roughly represent one year's traffic.

\section{Calibration of the matrix-based tactile surface sensors}

The pressure mats were calibrated to an absolute reference by placing a known mass directly onto the sensor and adjusting the sensitivity of the sensor to correspond with the test load. The protective rubber membranes were not used as part of this calibration procedure. It should be noted that the membranes would have an effect on the measured pressure distribution, but not on the total measured load. The 
objective of the use of the surface sensors was, however, not to measure the exact pressure distribution at the sleeper and USP interface, but rather to facilitate comparative analyses between the different experimental setups.

\section{RESULTS AND DISCUSSION}

The results from the two experiments described above are analysed and discussed in the following paragraphs under the following headings: ballast contact area and contact pressure, ballast settlement, ballast breakdown and elastic (pad) recovery.

\section{Ballast contact area and contact pressure}

It is known that the contact area between the underside of a concrete sleeper and new ballast stone is between $3 \%$ and $5 \%$ of the total area of a sleeper (Potocan \& Dorfner 2013).

During Experiment 1, static and dynamic loading tests were carried out under similar conditions with and without the USP between the sleeper and the ballast. For the static loading tests the total load on the sleeper was slowly increased from $0 \mathrm{kN}$ to $50 \mathrm{kN}$. The load was restricted to $50 \mathrm{kN}$ to prevent damage to the pressure sensors. During the dynamic tests, the load was cycled at a frequency of $2 \mathrm{~Hz}$ between $2 \mathrm{kN}$ and $50 \mathrm{kN}$. Each dynamic test consisted of 200 cycles.

The unloaded state was defined as the loading of the sleeper only with no external load. The unloaded contact area was between $5 \%$ and $6 \%$ without a USP. With a USP, the unloaded contact area was between $10 \%$ and $11 \%$.

Figure 5 shows a summary of the static and dynamic test results highlighting the effect of USPs on contact area and contact pressure. The values shown here are all for a maximum load of $50 \mathrm{kN}$. As expected, the higher contact pressure and contact area measurements are registered by pressure Mat A, the one directly below the point of load application. The results also illustrate the significant increase in the contact area between the ballast and sleeper when a USP is introduced. In the static test, the contact area between the ballast and sleeper under a load of $50 \mathrm{kN}$ increased from $12 \%$ of the total sleeper area (without a USP) to $35 \%$ on average as a result of the introduction of the USP. In a similar manner the average contact stress decreased from $1012 \mathrm{kPa}$ to $310 \mathrm{kPa}$, a significant reduction of $69 \%$.

In the dynamic test, the introduction of the USP increased the contact area under a load of $50 \mathrm{kN}$ from $8 \%$ to $28 \%$, and decreased the contact stress from $1029 \mathrm{kPa}$ to $310 \mathrm{kPa}$, an average reduction of $70 \%$.

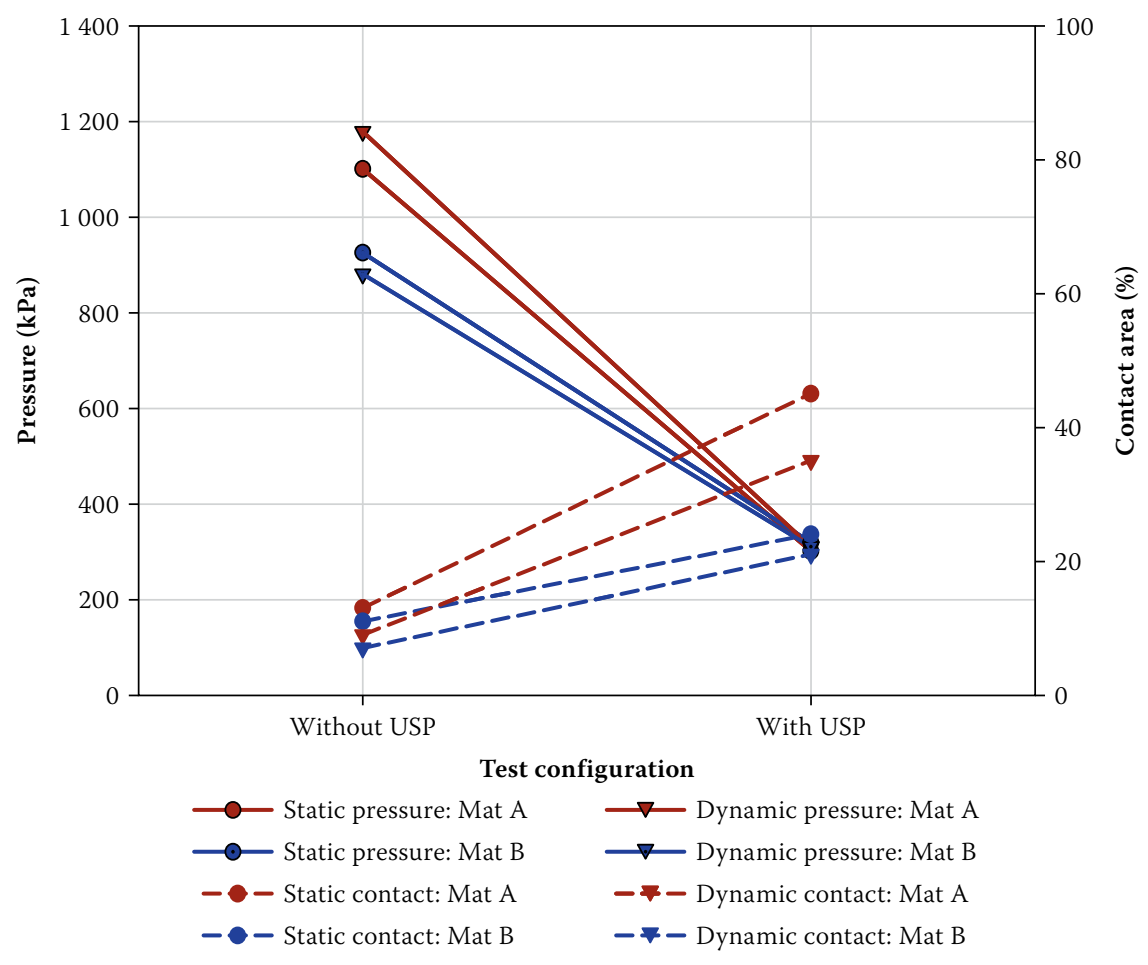

Figure 5 Pressure and contact area results for a total sleeper load of $50 \mathrm{kN}$ under static and dynamic testing

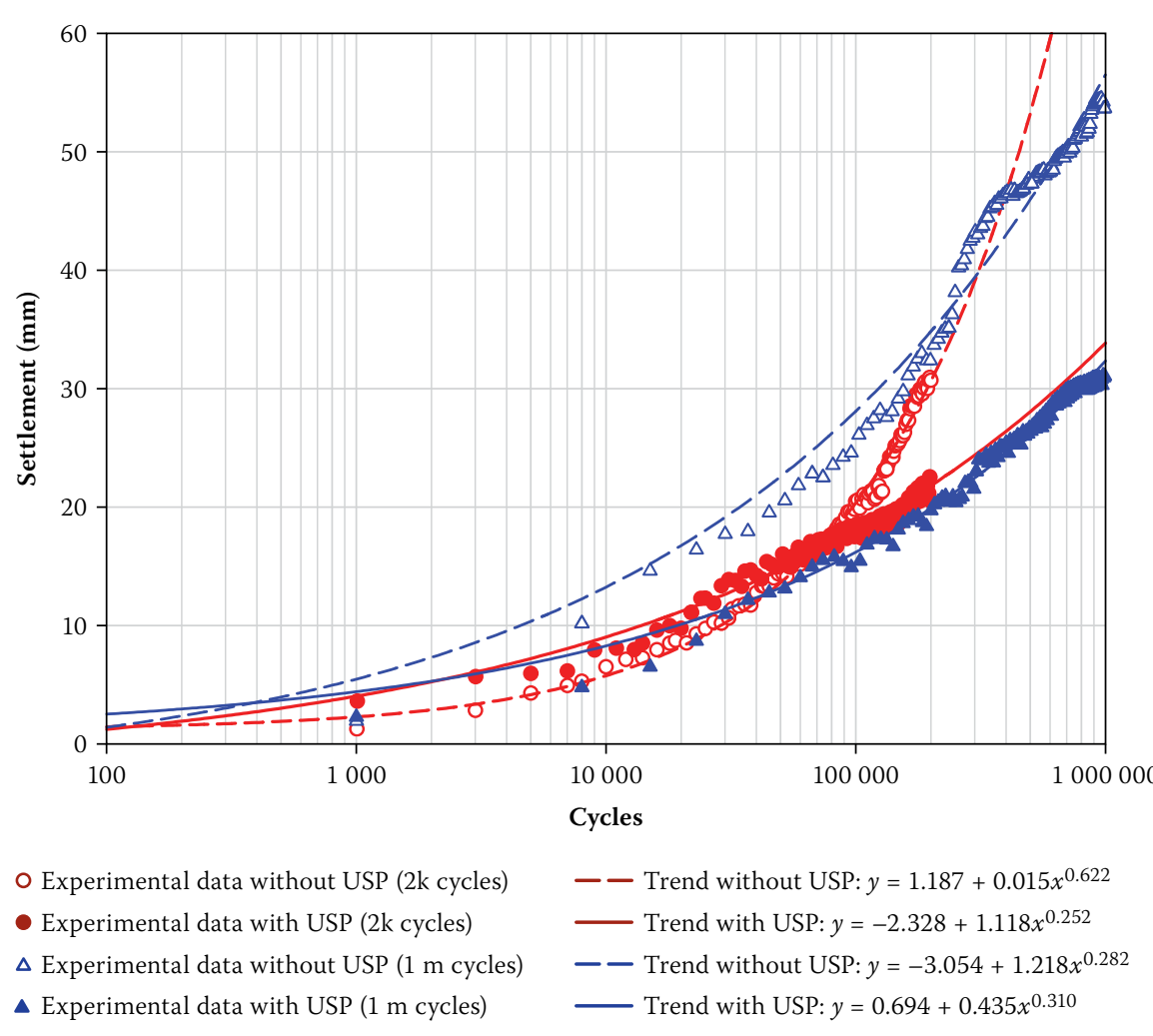

Figure 6 Settlement results of the 1000000 cycle test and the 200000 cycle test (Experiment 2)

\section{Ballast settlement}

Experiment 2 consisted of four different ballast settlement tests. The first two ballast settlement tests entailed a total of 1 million cycles each on a shortened sleeper $(1 \mathrm{~m}$ in length, as per the setup in Figure 4). The load was cycled between $1 \mathrm{kN}$ and $121 \mathrm{kN}$ at a frequency of $4 \mathrm{~Hz}$. The axle load on a typical heavy-haul line in South Africa is $26 \mathrm{t}$, which is equal to a force of approximately $260 \mathrm{kN}$ for a full concrete sleeper. Although a single sleeper in the track would normally not carry $100 \%$ of the axle load, it was nevertheless decided to retain this load to account for dynamic effects and extreme cases where overstressing of the sleepers takes place. 
Table 2 Sieve analysis results before and after Experiment 2 (1 million cycles)

\begin{tabular}{|c|c|c|c|c|}
\hline \multirow{3}{*}{ Sieve size $(\mathrm{mm})$} & \multicolumn{2}{|c|}{ Before testing } & \multicolumn{2}{|c|}{ After testing } \\
\hline & Without USP & With USP & Without USP & With USP \\
\hline & \multicolumn{4}{|c|}{ Mass retained on sieve $(\mathbf{k g})$} \\
\hline$<0.075$ & 0 & 0 & 0.118 & 0.020 \\
\hline 0.075 & 0 & 0 & 0.072 & 0.194 \\
\hline 0.15 & 0 & 0 & 0.488 & 0.210 \\
\hline 0.60 & 0 & 0 & 0.198 & 0.168 \\
\hline 1.18 & 0 & 0 & 0.622 & 0.508 \\
\hline 4.75 & 0 & 0 & 0.824 & 1.036 \\
\hline 13.20 & 0 & 0 & 1.388 & 0.662 \\
\hline 19 & 0.30 & 0.20 & 1.95 & 1.52 \\
\hline 26.6 & 8.65 & 7.85 & 11.20 & 10.83 \\
\hline 37.5 & 109.6 & 76.5 & 148.9 & 96.1 \\
\hline 53 & 173.4 & 181.6 & 150.8 & 184.7 \\
\hline 63 & 89.3 & 109.3 & 64.3 & 78.6 \\
\hline 75 & 0 & 0 & 0 & 0 \\
\hline Total mass & 381.3 & 375.4 & 380.8 & 374.5 \\
\hline Total fines $(<19 \mathrm{~mm})$ & 0 & 0 & $3.710(0.97 \%)$ & $2.798(0.74 \%)$ \\
\hline Mass loss & - & - & $0.5(0.13 \%)$ & $0.9(0.24 \%)$ \\
\hline
\end{tabular}

The load was consequently scaled down in relation to the area of the shortened (less than half) sleeper, resulting in a total load of $120 \mathrm{kN}$. To allow for consolidation of the ballast before the actual test commenced, 2200 cycles at half the total load were applied. In the first test the sleeper was loaded without the USP, while a USP was inserted between the sleeper and the ballast for the second test.

The cyclic load was applied in such a way that no moment would be transferred onto the sleeper, thereby allowing the sleeper to settle freely and unrestricted. During the first test without the USP, after roughly 100000 cycles, the sleeper tilted sideways due to uneven settlement of the ballast. A slight increase in the rate of settlement was also observed at this stage of the testing. The sleeper was repositioned with minimum disturbance to allow the test to continue to the full number of cycles.

Due to the problems with the uneven settlement of the sleeper during the 1 million cycle experiment, it was decided to perform a second ballast settlement test, this time only to a maximum of 200000 cycles. As before, the load was cycled between $1 \mathrm{kN}$ and $121 \mathrm{kN}$ at a frequency of $4 \mathrm{~Hz}$. The consolidation phase of the test involved 4000 cycles at half the maximum load.

Figure 6 shows the experimental settlement data of the 1 million cycle test and the 200000 cycle test. Power relationships of the form $y=y_{0}+a x^{b}$ where $x$ represents the number of cycles, $y_{0}$ the initial settlement and $a$ and $b$ shape parameters, were used to quantify the growth in settlement, as depicted by the trend lines in the same graph (Ebersöhn 1995).

It is interesting to note that a change in the rate of settlement occurred just after 100000 cycles in both tests involving the testing of the sleeper without a USP (see Figure 6). A possible explanation could be that this was the amount of loading or traffic required to bring about significant crushing of the ballast and cause an increase in the settlement rate. Figure 6 also shows the remarkable similarity between the settlement trends of the two tests where the USP was introduced. The tests without the USP, however, demonstrate different settlement rates and magnitudes, with the only similarity being the significantly higher settlement compared to the tests without the USP.

At the end of 1000000 cycles the sleeper without the USP settled $55.1 \mathrm{~mm}$, while the sleeper with the USP settled $31.1 \mathrm{~mm}$. This difference represents a $44 \%$ reduction in settlement as a result of the installation of the USP. Similarly, after 200000 cycles the sleeper without the USP settled $31.0 \mathrm{~mm}$, while the sleeper with the USP settled $22.5 \mathrm{~mm}$, a $27 \%$ reduction in settlement as a result of the use of the USP.

\section{Ballast breakdown}

As part of Experiment 2, the crushing of the ballast (or ballast breakdown) was investigated. The mass and grading of the ballast used in both tests were carefully recorded before and after the execution of each of the tests. This included a control test without a USP and a test with a USP. The same procedure was followed for both the 1 million cycle test and the 200000 cycle test, but because the cycles in the latter were limited, the results were not as prominent as those of the 1 million cycle test and they will not be presented here.

Table 2 shows the results of the grading analyses on the different ballast samples before and after the completion of the 1 million cycles. The following important aspects are highlighted by the data in Table 1 :

- Before commencing with the cyclic loading, the samples of ballast used for both tests contained no fines (aggregate smaller than $19 \mathrm{~mm}$ ).

- As a result of the cyclic loading, the fines (<19 mm) increased from $0 \mathrm{~kg}$ to $3.710 \mathrm{~kg}$ ( $0.97 \%$ of the total sample mass) and $2.798 \mathrm{~kg}(0.74 \%$ of the total sample mass) for the test without the USP and the test with the USP respectively. Although these figures are relatively small, the change in the fines increase (from $0.97 \%$ to $0.74 \%$ ) is $23 \%$ less as a result of the introduction of the USP.

Figure 7 shows the results of the grading analyses carried out on the different ballast samples used for Experiment 2. A logarithmic scale was used for the percentage passing the various sieve sizes so that the small particle size fractions of the material could be evaluated. The graph also shows the reduction in ballast breakdown that was calculated for all sieve sizes. The high reduction calculated for the aggregate $<0.075 \mathrm{~mm}$ could be regarded as unreliable, due to the extremely small mass of material involved. If this value is ignored, the average reduction in ballast breakdown as a result of the USP equates to $24 \%$. This average value correlates well with the $23 \%$ reduction in fines $(<19 \mathrm{~mm})$ that was calculated previously as a result of the use of the USP.

Further analysis of the data presented in Table 2 reveals that the largest particle size in the smallest $50 \%$ of particles $\left(D_{50}\right)$ $=53 \mathrm{~mm}$ for the ballast material before commencing with the cyclic loading on the sleeper without a USP. After the test the grading curve moves in the direction of smaller aggregate so that $D_{50}=45 \mathrm{~mm}$. For the cyclic loading test with a USP, $D_{50}=53 \mathrm{~mm}$ before the test and remains at the same value even after completion of the 1 million cycles. This observation also supports the notion that ballast degradation is significantly reduced by using USPs.

\section{Elastic (pad) recovery}

A final aspect that was considered in the evaluation of the effect of a USP on sleeperballast interaction was the elastic recovery of the pad. After completion of the tests in Experiment 2, the pads were removed from 
the sleeper-ballast interface and allowed to recover in the absence of any loading. Figure 8 shows how the severe indentations as a result of the ballast pushing into the pad, and in one case tearing the pad, disappeared almost completely after 24 hours. Future tests on USPs are planned during which the structural properties of the pad will be evaluated before and after stages (i.e. increments of 100000 repetitions) of cyclic loading.

\section{CONCLUSIONS}

The objective of this paper was to evaluate the effect of under-sleeper pads on four aspects related to sleeper-ballast interaction. These included ballast contact area, contact pressure, ballast settlement and ballast breakdown, specifically under heavy-haul conditions as opposed to passenger and general freight traffic.

In the first experiment it was found that the unloaded contact area between the ballast and the underside of a PY (heavy-haul) sleeper is between $5 \%$ and $6 \%$ without an under-sleeper pad. During a static test on the sleeper from $0 \mathrm{kN}$ to $50 \mathrm{kN}$, the introduction of the USP resulted in a contact area increase from $12 \%$ without a USP to $35 \%$ with a USP, while the contact stress was reduced by $69 \%$. A dynamic test in which the sleeper load was cycled between $2 \mathrm{kN}$ and $50 \mathrm{kN}$ produced similar results, with a contact area increase from $8 \%$ to $20 \%$ and an average reduction of $70 \%$ in the contact pressure.

The second experiment involved the application of 1 million and then

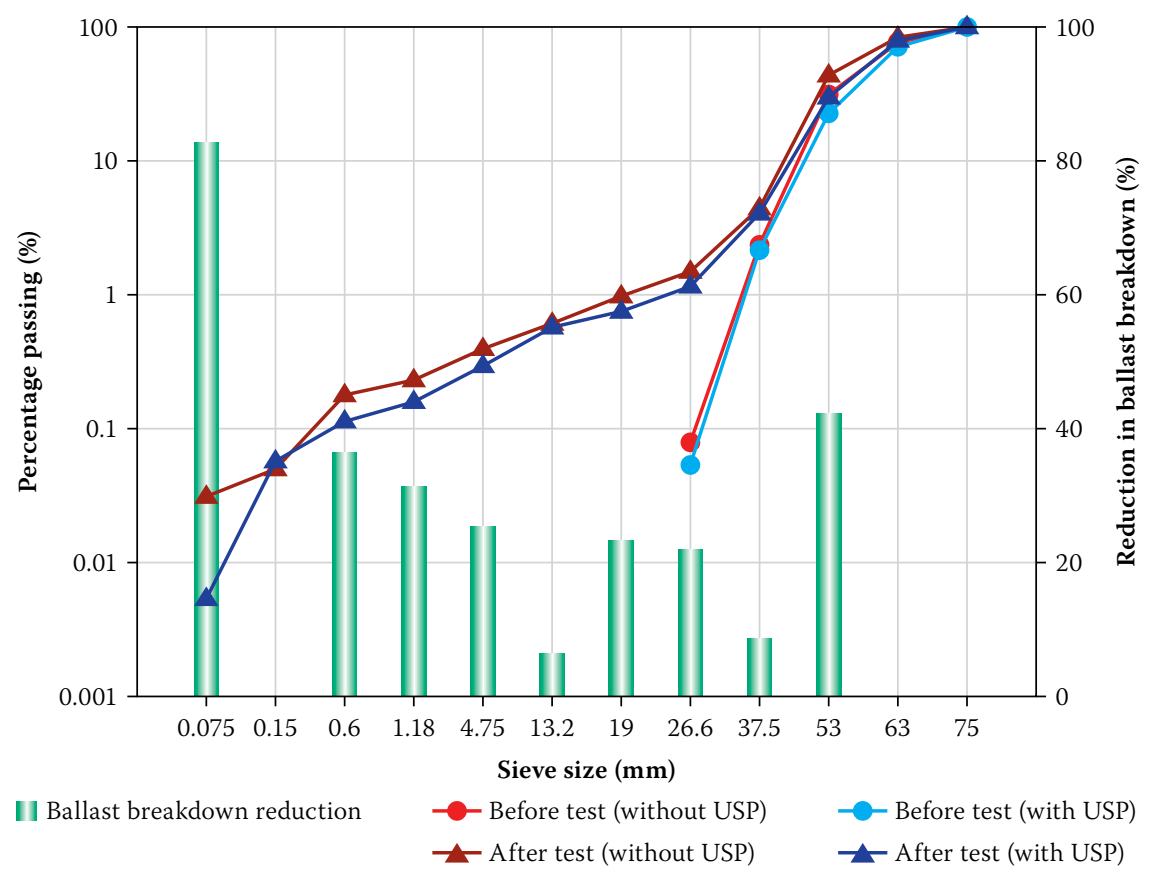

Figure 7 Ballast breakdown results of the 1 million cycle test (Experiment 2)

200000 cycles between $1 \mathrm{kN}$ and $121 \mathrm{kN}$ on half a sleeper with and without a USP. The installation of the USP resulted in a $44 \%$ reduction in the total settlement after 1 million cycles. The second settlement test to a total of 200000 cycles showed a $27 \%$ reduction in the settlement of the half sleeper as a result of the USP. The ballast used in the second experiment was graded before and after the application of the 1 million loading cycles. The aggregate used in both tests (with and without the USP) experienced ballast breakdown as a result of the high cyclic loads. However, the USP reduced the breakdown of the ballast across all particle sizes by an average of $24 \%$. Similarly, the amount of fine aggregate $(<19 \mathrm{~mm})$ was $23 \%$ less when a USP was used. In terms of ballast grading, the $d_{50}$ value of the new ballast was reduced from $53 \mathrm{~mm}$ to $45 \mathrm{~mm}$ in the test without a USP, while the $d_{50}$ value of the ballast material with the USP remained unchanged at $53 \mathrm{~mm}$. Visual observations indicated good to excellent elastic recovery of the used pad 24 hours after the 1 million cycle test.
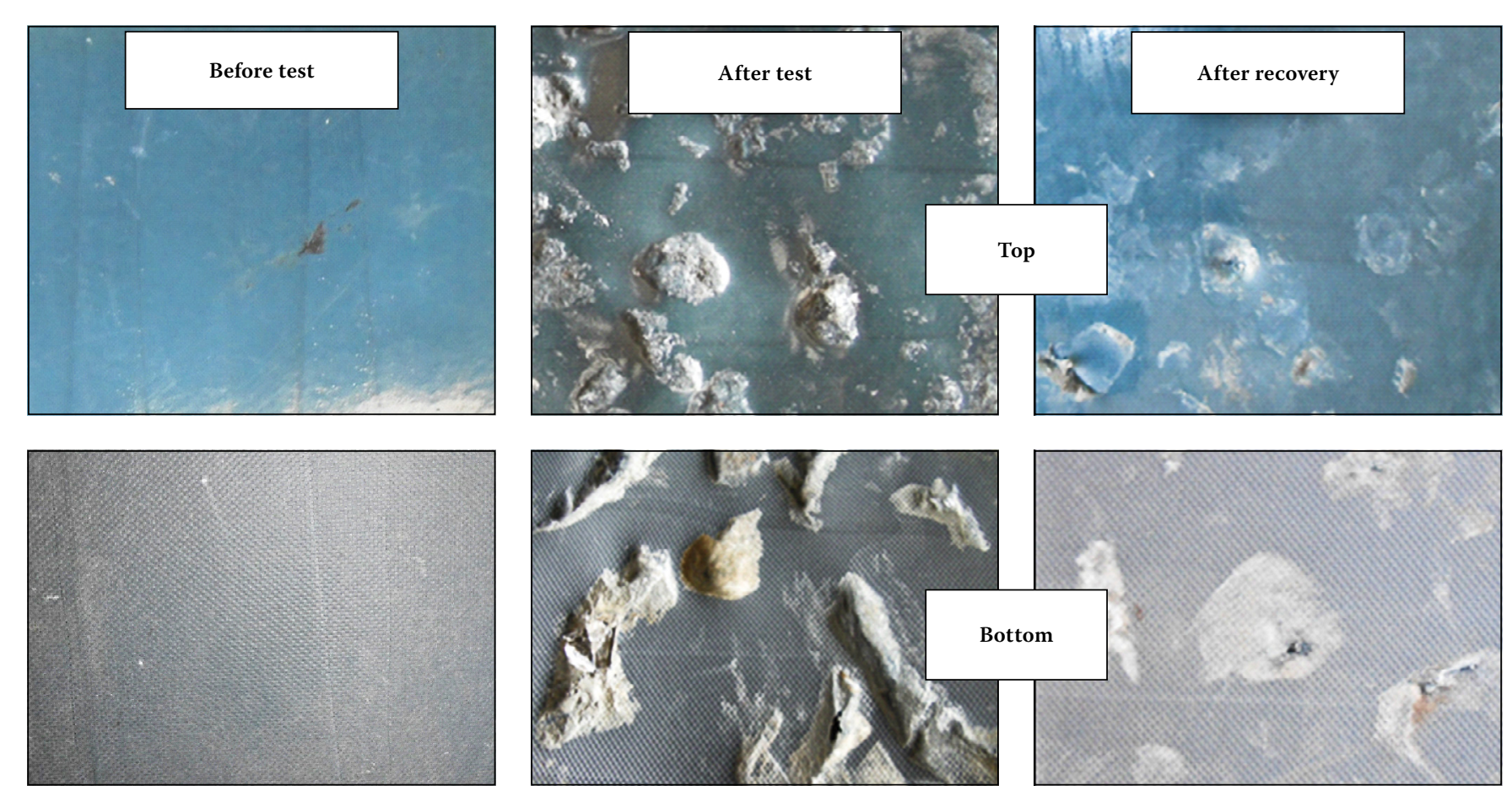

Figure 8 Condition and appearance of the USP before and after Experiment 2 (1 million cycles) and after a recovery period of 24 hours 
In conclusion it can be stated that the introduction of USPs on heavy-haul lines, as demonstrated by the two experiments described in this paper, offers significant advantages with respect to ballast settlement and breakdown. It was shown in the paper that an increase in sleeper-ballast contact area and a subsequent reduction in the contract pressure result from the placement of a USP between the sleeper and the ballast. A subsequent reduction in ballast settlement and breakdown under cyclic loading was directly attributed to the introduction of the USP. These advantages are most likely to lengthen the ballast tamping and screening cycles, resulting in significant life cycle cost savings. Subject to long-term structural performance and fatigue as a result of cyclic loading and adverse environmental conditions, the use of under-sleeper pads should be considered as a viable addition and possible improvement to existing heavy-haul infrastructure technology.

\section{ACKNOWLEDGEMENTS}

Transnet Freight Rail is gratefully acknowledged for financial support to the Chair in Railway Engineering at the University of Pretoria. The authors wish to thank the following staff members of the Department of Civil Engineering at the university for assisting with the laboratory tests, specialisd equipment and writing of this paper: Prof Wynand VdM Steyn, Mr Johan Scholtz, Mr Derek Mostert, Mr Jaco Vorster, Mr Rudolph du Plooy and Mr Paul Vorster.

\section{REFERENCES}

Ebersöhn, W 1995. Substructure influence on track maintenance requirements. PhD thesis, Amherst, MA: University of Massachusetts, Department of Civil and Environmental Engineering.

Esveld, C 2001. Modern Railway Track, 2nd ed. The Netherlands: MRT-Productions

Johansson, A, Nielsen, J C O, Bolmsvik, R, Karlström, A \& Lundén, R 2008. Under sleeper pads - Influence on dynamic train-track interaction. Wear 265(9): 1479-1487.

Loy, H 2008. Under sleeper pads: Improving track quality while reducing operational costs. European Railway Review, 4: 46-51.

Maree, J S \& Gräbe, P J 1997. Use of a dynamic track stabiliser to improve track maintenance and optimization of track tamping. Proceedings, 6th International Heavy Haul Conference, Cape Town, June, pp 945-957.
Marschnig, S \& Veit, P 2011. Making a case for undersleeper pads. International Railway Journal, 51: 27-29.

Potocan, S \& Dorfner, T 2013. Under sleeper pads for life cycle management used in building sustainable high quality tracks. Proceedings, 10th International Heavy Haul Association Conference, New Delhi, India, February, Vol 1 pp 117-122.

Schilder, R \& Auer, F 2009. Technical and economical aspects to Under Sleeper Pads - Part 1: Long-term experiences in the ÖBB-network (in German). ZEVrail, 133(5): 180-193.

Selig, E T \& Waters, J M 1994. Track Geotechnology and Substructure Management. London: Thomas Telford.

Transnet Freight Rail (TFR) 1998. S406 - Specification for the supply of stone. Johannesburg: TFR.

Veit, P \& Marschnig, S 2009. Technical and economical aspects to Under Sleeper Pads - Part 2: Economic efficiency in the ÖBB-network. ZEVrail, 133(11-12): $436-443$.

Veit, P \& Marschnig, S 2013. Dedicated freight corridors - A case for Under Sleeper Pads. Proceedings, 10th International Heavy Haul Association Conference, New Delhi, India, February, Vol 1 pp 134-138.

Witt, S 2008. The influence of Under Sleeper Pads on railway track dynamics. Report LIU-IEIA-08/00442-SE. Linköping, Sweden: Linköping University 